$\underline{\text { REVIEW }}$

\title{
A review of the pathomechanism of forward slippage in pediatric spondylolysis : The Tokushima theory of growth plate slippage
}

\author{
Koichi Sairyo, Akihiro Nagamachi, Tetsuya Matsuura, Kosaku Higashino, Toshinori Sakai, Naoto Suzue, \\ Daisuke Hamada, Yoichiro Takata, Tomohiro Goto, Toshihiko Nishisho, Yuichiro Goda, Takahiko Tsutsui, \\ Ichiro Tonogai, Ryo Miyagi, Mitsunobu Abe, Masatoshi Morimoto, Kazuaki Mineta, Tetsuya Kimura, Akihiro Nitta, \\ Tadahiro Higuchi, Shingo Hama, Subash C. Jha, Rui Takahashi, and Shoji Fukuta. \\ Department of Orthopedics, Tokushima University, Tokushima, Japan
}

\begin{abstract}
Spondylolysis is a stress fracture of the pars interarticularis, which in some cases progresses to spondylolisthesis (forward slippage of the vertebral body). This slip progression is prevalent in children and occurs very rarely after spinal maturation. The pathomechanism and predilection for children remains controversial despite considerable clinical and basic research into the disorder over the last three decades. Here we review the pathomechanism of spondylolytic spondylolisthesis in children and adolescents, and specifically the Tokushima theory of growth plate slippage developed from our extensive research findings. Clinically, we have observed the slippage site near the growth plate on MRI ; then, using fresh cadaveric spines, we found the weakest link against forward shear loading was the growth plate. We subsequently developed an immature rat model showing forward slippage after growth plate injury. Moreover, finite element analysis of the pediatric spine clearly showed increased mechanical stress at the growth plate in the spondylolytic pediatric spine model compared with the intact pediatric spine. Thus, spondylolysis progresses to spondylolisthesis (forward slippage) in children and adolescents with the growth plate as the site of the slippage. Repetitive mechanical loading on to the growth plate may serve to separate the growth plate and subsequently progress to spondylolisthesis. J. Med. Invest. 62 : 11-18, February, 2015
\end{abstract}

Keywords : Spondylolysis, spondylolisthesis, growth plate, adolescents, children

\section{INTRODUCTION}

Lumbar spondylolysis, a stress fracture of the pars interarticularis, commonly occurs in children and adolescents (1-5). Few articles have described fresh stress fractures at the pars in adults over 20 years of age (6). Once pseudoarthrosis occurs, spondylolysis may progress to spondylolisthesis, involving forward slippage of the lytic spine. Similarly, the literature contains numerous reports of slippage in children and adolescents, but very few after spinal maturation in adults (7-12). It would seem reasonable then to assume that such slippage would occur at a specific anatomical location in pediatric patients ; however, the underlying pathomechanism is not yet completely understood. Over the last 30 years, the Department of Orthopedics at Tokushima University, Japan, has conducted various clinical and basic research into the slippage mechanism in children and adolescents. In this review article, we describe the pathomechanism of slippage in the spondylolytic spine and review the Tokushima theory of growth plate slippage that was developed over decades of research in our department.

\section{SPONDYLOLYSIS : THE BASIC LESION IN SPONDY- LOLISTHESIS}

Figure 1 shows a three-dimensional posterior view and axial CT

Received for publication November 25, 2014 ; accepted January 23, 2015.

Address correspondence and reprint requests to Koichi Sairyo, MD and PhD Professor and Chairman, Department of Orthopedics, Tokushima University 3-18-15 Kuramoto, Tokushima 770-8503, Japan and Fax : + 81-88-633-0178. scan of lumbar spondylolysis, with arrows indicating the pars defects. Initially, spondylolysis was considered a congenital anomaly. However, current consensus is that the pathogenesis of spondylolysis involves a stress fracture at the pars interarticularis (3), based on the following evidence.

1 : Spondylolysis has never been observed in neonates (13).

2 : Rosenberg reported that spondylolysis does not occur in nonambulatory patients (14), and Sakai et al. reported lumbar spondylolysis occurs only in patients with cerebral palsy who have involuntary repetitive movements of the trunk in daily life (15).

3 : The time course of lumbar spondylolysis from occurrence to progression to pseudoarthrosis is similar to that of stress fracture of the long bone. As shown in Figure 2, our group at Tokushima University have proposed classifying spondylolysis into three stagesearly, progressive, and terminal $(2,5,16-20)$. In the early stage, the defect is faint and seen only as bone absorption on CT ; in the progressive stage, the defect manifests as complete fracture of the pars interarticularis; and in the terminal stage, the defect has the features of pseudoarthrosis.

As the motions of extension and rotation may hold a clue to the pathomechanism of the pars stress fracture $(21,22)$, a brace is often recommended to immobilize the spine and thus restrict spinal rotation and extension (20). If spondylolysis is found in the early stage, the defect can heal osseously in about $90 \%$ of patients in around 3 months (20). However, the union rate decreases in the progressive stage, and when conservative treatment is not effective, the defect progresses to the terminal stage (pseudoarthrosis). The pediatric spine with terminal-stage spondylolysis could then progress to slippage. 


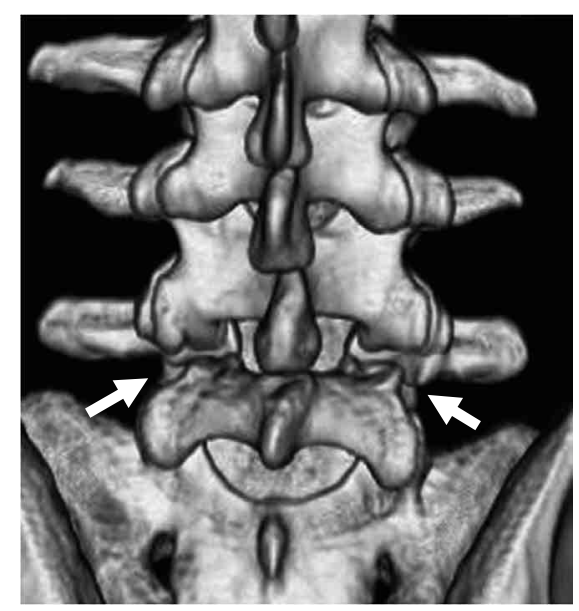

(a) 3D-CT posterior view

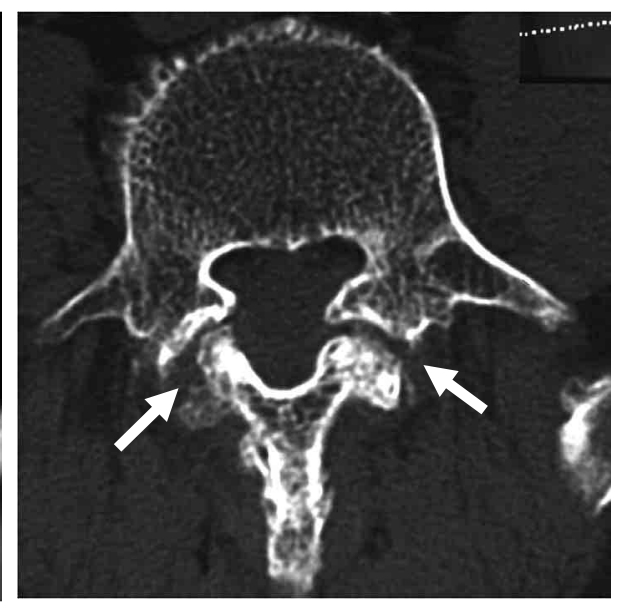

(b) Axial CT

Figure 1 : Lumbar spondylolysis seen on (a) a three-dimensional CT and (b) axial CT. Arrows indicate the location of the pars defects.

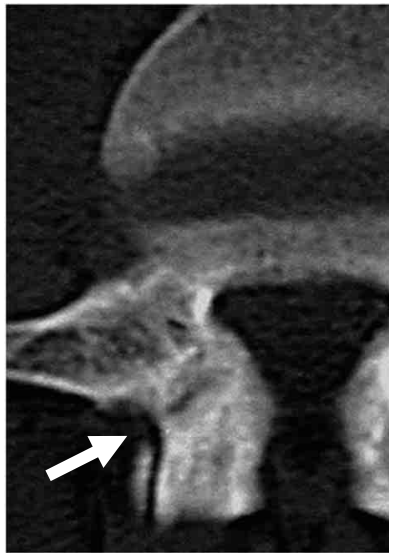

(a) Early

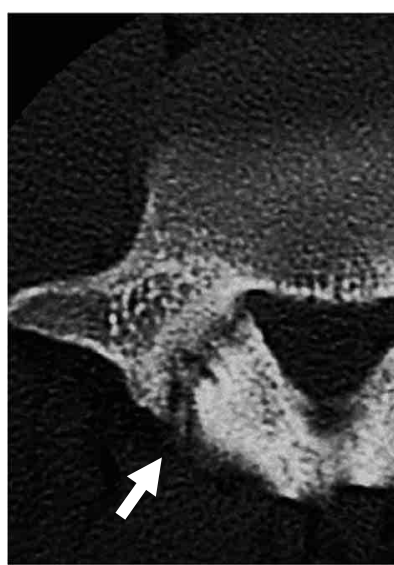

(b) Progressive

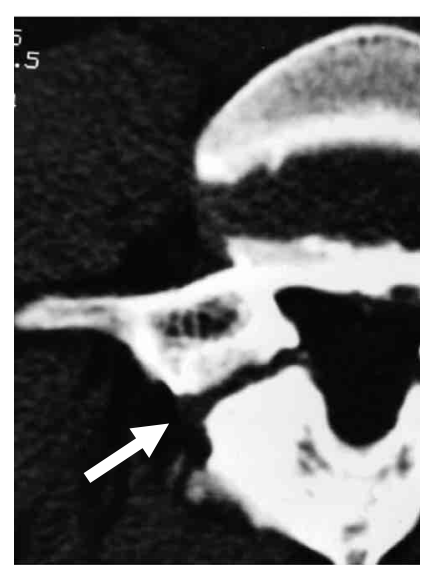

(c) Terminal

Figure 2 : CT scans of the stages of lumbar spondylolysis proposed by Tokushima University research groups. (a) The early stage defect is faint and is only seen as bone absorption on CT. (b) The progressive stage defect involves a complete fracture of the pars interarticularis. (c) The terminal stage defect has features of pseudoarthrosis. Arrows indicate the location of the pars defects.

\section{WHEN DOES SLIPPAGE OCCUR?}

Once the pars defect is completed in the terminal stage of the spondylolysis, the vertebral body is no longer connected with the facet joint. Consequently, the vertebral body is likely to slip forward. Figure 3 shows plain radiographs and an MR image of isthmic spondylolysis, with the vertebral body showing forward slippage. Figure 3a shows moderate slippage, while Figure 3b,c shows severe slippage.

Slippage is rare after spinal maturation (7-12). Figure 4 shows the skeletal age of the lumbar spine through different stages. In the cartilaginous stage (Figure 4a), the secondary ossification center of the vertebral body is not seen radiographically. In this stage, the disc space looks wider than the vertebral body width, and the vertebral body has rounded corners of the vertebral body (arrows). In the apophyseal stage, the secondary ossification center is observed (arrows, Figure $4 \mathrm{~b}$ ). This stage typically involves the growth spurts seen in adolescence. In the epiphyseal stage, the apophyseal ring fuses to the vertebral body, suggesting that the vertebra has reached maturation (Figure 4c). The edges of the vertebral body are now sharp and clearly different from those in the cartilaginous stage. Early studies reported that slippage is prevalent in children and adolescents but rare after spinal maturation (7-11), but there was little precise information on the relation between slippage and skeletal age at that time.

Our group were the first to report the relation between bony age on slippage based on data from 46 athletes aged under 18 in 2001 (12). The average follow-up period was 6.0 years. We found clear findings of slippage at certain bony ages (arrows, Figure 5) : first, from the cartilaginous stage to the apophyseal stage $(80 \%$, $16 / 20$ cases ; ) and second, from the cartilaginous stage to the epiphyseal stage(11.1\%, 3/27 cases). Conversely, no slippage was seen after the epiphyseal stage in any of 22 patients with a mature spine. Thus, among pediatric patients with an immature spine 


\section{Case 1}

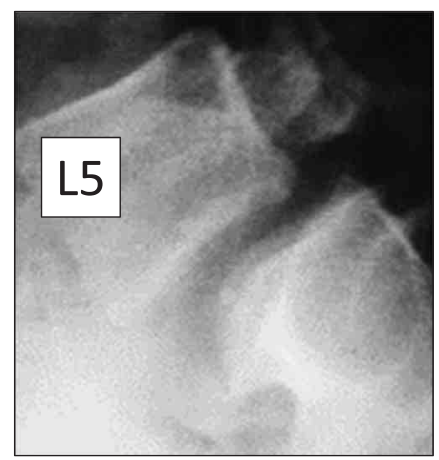

(a) Plain radiograph

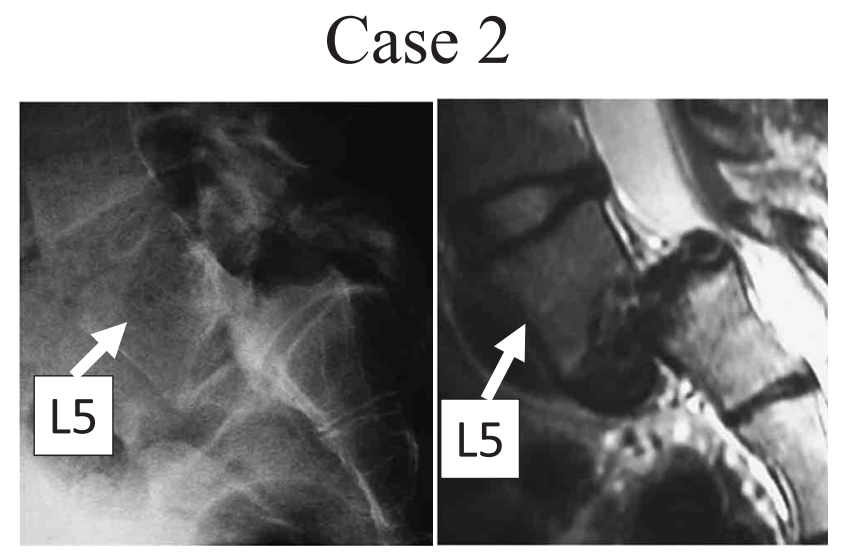

(b) Plain radiograph (c) MRI

Figure 3 : Imaging of isthmic spondylolysis where the vertebral body has slipped forward. (a) Plain radiograph in Case1 shows a moderate slip. In Case 2, (b) a radiograph shows a high degree of slippage (arrow) and (b)MRI shows severe slippage (arrow).

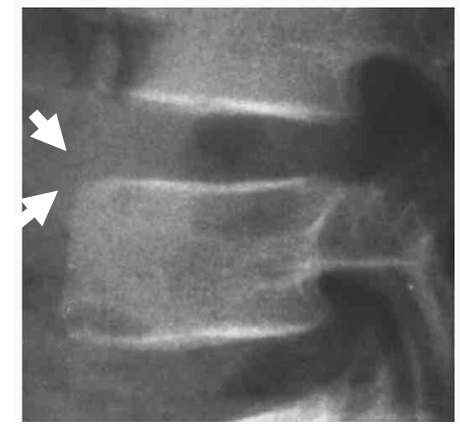

(a)

Cartilaginous
stage

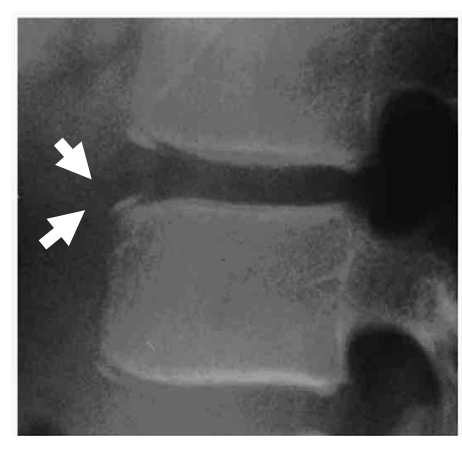

(b)

Apophyseal
stage

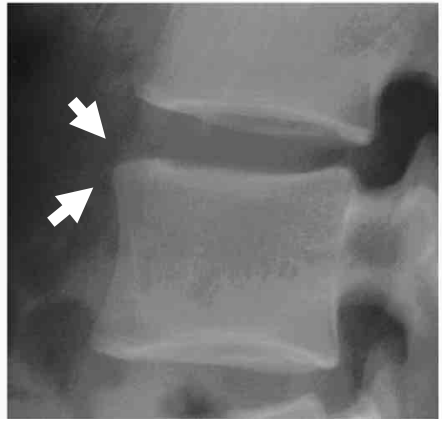

(c)

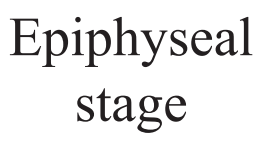

Figure 4 : Radiographs showing changes in the lumbar spine according to skeletal age. (a) In the cartilaginous stage, the secondary ossification center of the vertebral body is not evident, the disc space is wider than the vertebral body width, and the vertebral body has rounded edges (arrows). (b) The apophyseal stage shows the secondary ossification center (arrows). (c) In the epiphyseal stage, the apophyseal ring fuses to the vertebral body, suggesting that the vertebra has reached maturation and the vertebral body has sharp edges (arrows).

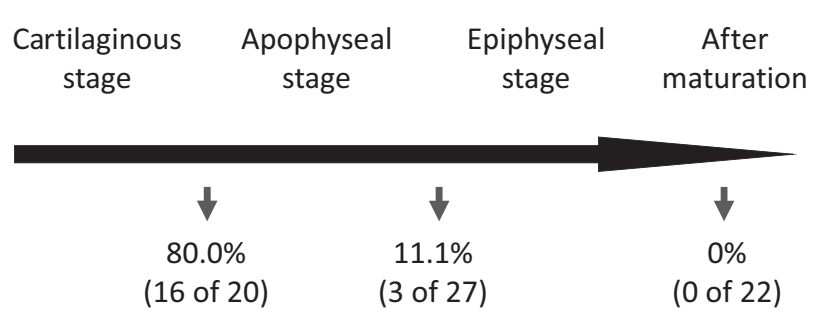

Figure 5 : Relation between bony age and slippage. Slippage was seen more frequently seen from the cartilaginous stage to the apophyseal stage $(80.0 \%, 16 / 20$ cases) and from the cartilaginous stage to the epiphyseal stage (11.1\%, $3 / 27$ cases). No slippage occurred after the epiphyseal stage ( $0 / 22$ cases) and terminal stage spondylolysis, maturation of the vertebral body appeared to be the most important factor for predicting consequent slippage. Clinically, this indicates that pediatric athletes with spondylolysis or slippage in whom spinal maturation has reached the epiphyseal stage can participate in sports activities without risk of further slippage. However, athletes with spinal maturation at the cartilaginous stage require special attention because they are at risk of further progression of the slippage. The results of a biomechanical study using fresh cadaveric calf spines that we published in the same year clearly supported our clinical findings (23). We found that the biomechanical strength of the growth plate against shear force is weak in the immature spine but increases with spinal maturation. 


\section{WHERE DOES SLIPPAGE OCCUR?}

The location of slippage in pediatric patients with lumbar spondylolysis remains controversial. Radiologically, it is reasonable to consider that slippage occurs at the disc, as indicated by Saraste in 1993 (24). Seitsalo et al. (25) examined this theory by measuring disc degeneration on MR images in 227 patients with isthmic spondylolisthesis under 20 years of age. They found a significant association between degree of slippage and severity of disc degeneration. However, if this were actually the case, it would make it extremely difficult to explain why slippage is rare after spinal maturation.

In 1976, Farfan et al. (26) had suggested that slippage is prevalent in children mainly because of an epiphyseal separation following growth plate injury. Few other clinical and basic research studies were being conducted at that time to address where slippage was occurring. However, in the 1980s, a research group from Tokushima University (Chief researcher, Prof. Ikata, who is deceased in 2013) hypothesized that slippage in the pediatric spine with spondylolysis would not in fact be similar to that in the adult spine. Based on meticulous observations of MR images, they proposed that slippage in children might occur at a specific location between the cartilaginous and osseous endplates. In 1996, they reported, for the first time, this concept of endplate slippage as the Tokushima theory (27). Figure 6 shows the imaging findings of a pediatric patient with spondylolytic spondylolisthesis. Figure $6 \mathrm{a}$ is a plain radiograph indicating deformity after growth plate injury (arrows), and Figure 6b is an MR image of the slippage site in the endplate (arrows).

To prove this hypothesis, the Tokushima group started a collaborative biomechanical study with Prof. Vijay K. Goel of the University of Iowa in USA. Biomechanical investigations using fresh cadaveric calf spines (28) and baboon spines (29) confirmed in experimentally created spondylolysis that the weakest biomechanical link in the immature spine was the growth plate. Figure 7 shows radiographs and schematic explanations before and after slippage of the immature fresh calf spine (28). The data strongly indicated the growth plate as the location for forward slippage in pediatric patients with lumbar spondylolysis. These biomechanical results are in good agreement with the concept of endplate slippage put forward by the proposed Tokushima theory (27), since the growth plate of the vertebral body is located between the cartilaginous and osseous endplates in children and adolescents. On the basis of this, the Tokushima theory of endplate slippage was modified to the Tokushima theory growth plate slippage. Now, with the inclusion of both clinical $(27)$ and biomechanical $(28,29)$ findings, the Tokushima theory was seen to correspond to the hypothesis proposed by Farfan et al. two decades earlier (26).

As a next step, in 2000, Tokushima group attempted to create an animal model mimicking pediatric spondylolytic spondylolisthesis and used the model to conduct basic research (30-33). Using a 4week-old rat, model because slippage is common at a youngest skeletal age (12), we performed posterior destabilization surgery, and evaluated slippage and subsequent spinal deformities on weekly radiographs until 3 weeks after the surgery. Spine samples were then evaluated histologically. The results are shown in Figure 8. Forward slippage was observed in $10 \%$ of the operated animals at 1 week after the surgery. At 3 weeks after the surgery, the spine showed a rounding and wedging deformity with a growth plate injury (Figure $8 \mathrm{c}$, blue arrows in inset). Thus, after posterior destabilization, the immature rat model could mimic the spinal deformities in pediatric isthmic spondylolisthesis. The histological examination demonstrated growth plate separation. Thus, the model supported the Tokushima theory of growth plate slippage.

To further understand growth plate slippage, it was important to clarify the biomechanics of the growth plate during lumbar motion in the pediatric spine with or without spondylolysis. For this purpose, finite element (FE) analysis is most appropriate, since mechanical stress and its distribution can be understood clearly using this method. FE analyses have been widely conducted for a variety of surgical methods and spinal disorders in the adult spine (e.g., the pedicle screw system (34), artificial disc (35), pars screwing (22), decompression surgery (36), lumbar spondylolysis (2, $16,21)$, spinal canal stenosis (37), and spina bifida occulta (38)). The FE model used in these studies was developed by Prof. Vijay K. Goel at the University of Toledo. The Tokushima group started developing an FE model of the pediatric spine in collaboration with the University of Toledo in 2005.

The well-established adult FE model was modified to create the pediatric model (39-41). The model was of the pediatric spine in the apophyseal stage . In humans, apophyseal ring ossification

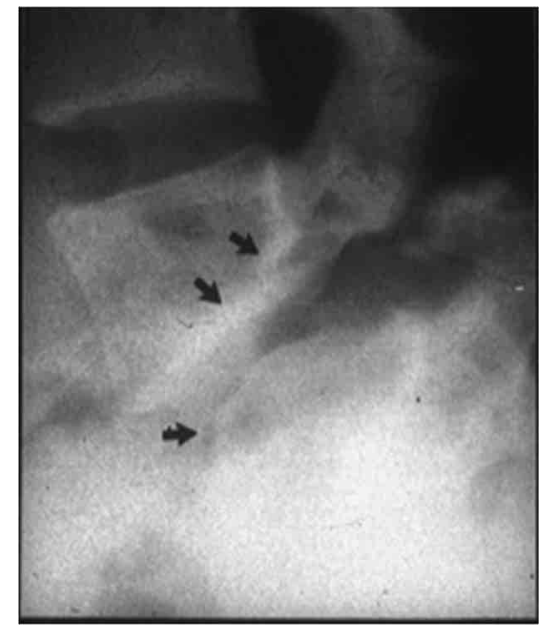

(a) Plain radiograph

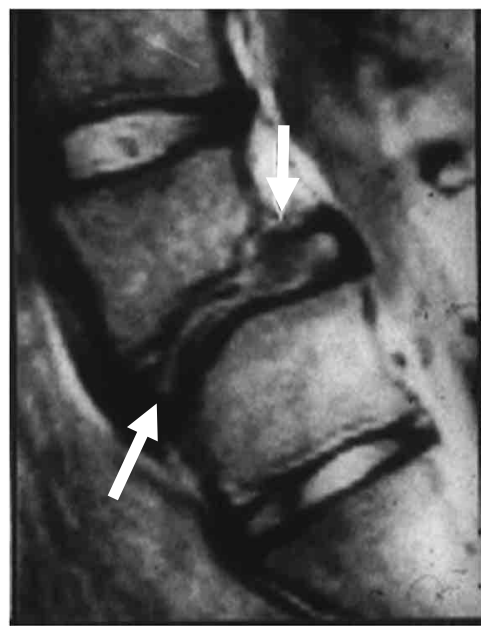

(b) MRI

Figure 6 : Imaging of a pediatric patient with spondylolytic spondylolisthesis. (a) Black arrows on the plain radiograph indicate deformity after growth plate injury. (b) White arrows on MRI indicate the slippage site in the endplate. 


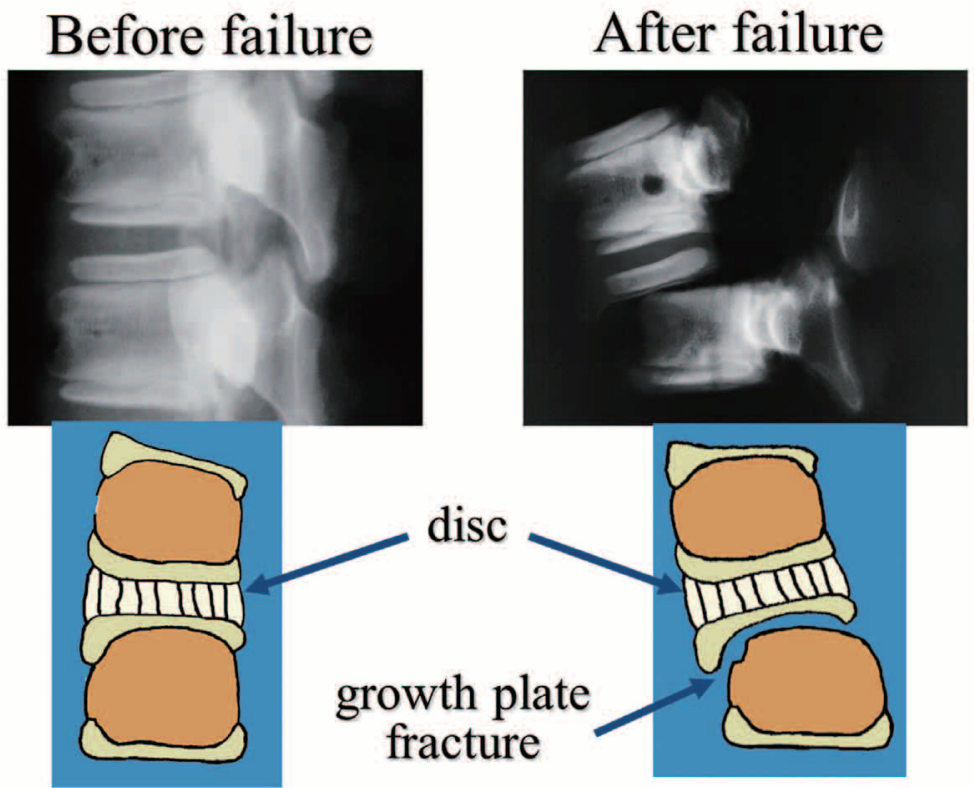

Figure 7 : Before and after failure against forward loading seen on radiographs and in schematics. The weakest link in the immature spine is the growth plate, and current data strongly support that the growth plate as the site of forward slippage in pediatric patients with lumbar spondylolysis.
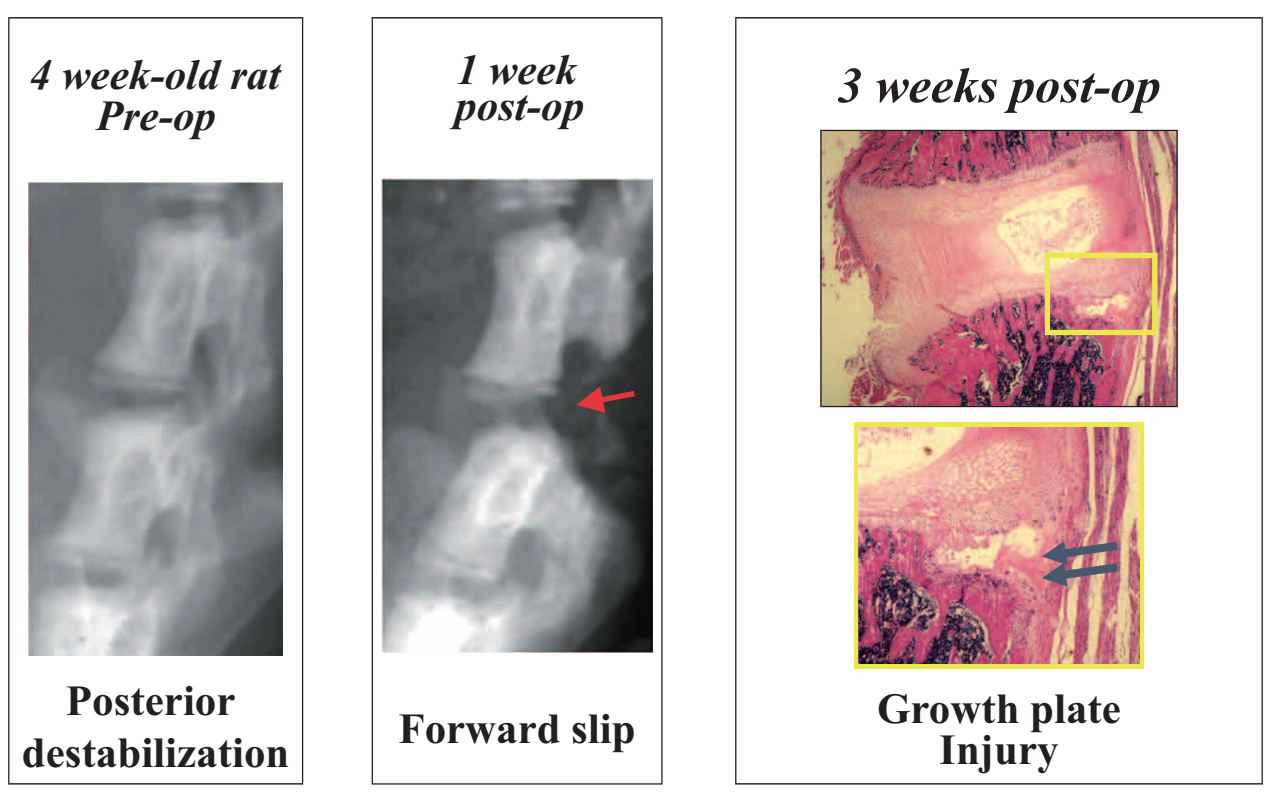

Figure 8 : Plain radiographs and histology in the immature spine slippage animal model. Slippage was observed in $10 \%$ of the animals at 1 week after posterior destabilization surgery. At 3 weeks after the surgery, the spine showed rounding and wedging deformity with growth plate injury histologically. Thus, posterior destabilization in the immature rat model could mimic the spinal deformities occurring in pediatric isthmic spondylolisthesis.

occurs around 10-15 years of age. Taking the ratio of mean sitting height in adults and 14-year-old children, we reduced the size of the adult spine model to $96 \%$ of its original size (39) and added growth plates and apophyseal bony rings. That characterize the pediatric spine. Figure 9 shows the pediatric FE model with the apophyseal ring and growth plate. A pars defect, representing lumbar spondylolysis, could be included in the model. Motion behavior was compared between the intact pediatric spine with and without a pars fracture and revealed that the stresses in all structures, including the growth plate, apophyseal bony ring, and endplate, increased after spondylolysis in all loading modes. Extension showed the highest increase in stress with a pars fracture, around 6 -fold at the growth plate when compared with the intact model (40). Based on these data, we concluded that the stress concentrations exerted on the growth plate during lumbar motion in the lytic spine could lead to physis stress fracture and eventually spondylolisthesis. 


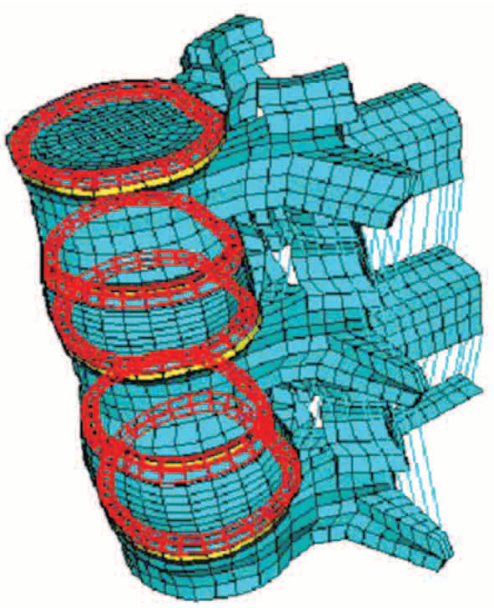

(a) Apophyseal bony ring

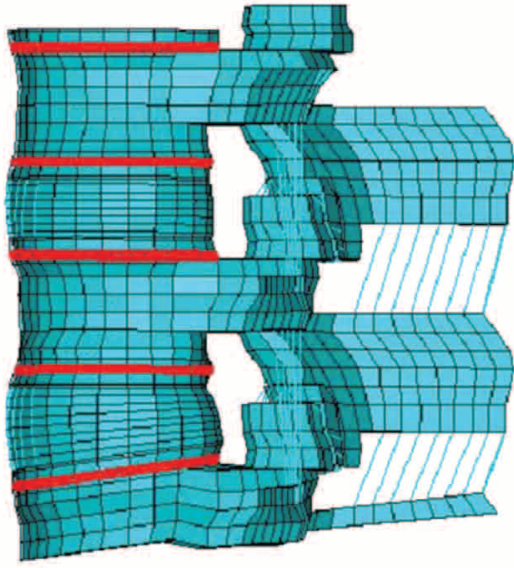

(b) Growth plate

Figure 9 : The finite element model of the pediatric spine with (a) apophyseal rings and (b) growth plates shown in red.

\section{PEDIATRIC SLIP OR ADULT SLIP?}

While the occurrence of slippage is very frequent in childhood and adolescence but very rare in the mature spine, isthmic spondylolisthesis can occur after maturation (42-44). In adults, there is no growth plate, which is the location of slippage in the pediatric population, so the slippage occurs at the intervertebral disc due to degeneration and dysfunction of the disc. Thus, the slippage site differs between pediatric and adult patients with a spondylolytic spine. Figure 10 shows the typical lateral view of plain radiographs for slippage in children and adults. Figure 10a shows pediatric slippage, where the growth plate is involved in the slippage ; as a result, spinal deformity is frequently associated with this condition. The black arrows indicate deformity of the L5 vertebral body, and the body has a wedge-like shape. The white arrow indicates poor development of the anterior edge of the S1 vertebral body, a malformation known as a dome-like deformity of the sacrum. For comparison, Figure 10b shows adult slippage. The vertebral body is almost square, the anterior edge of the sacrum is sharp as is normal (arrow), and there is no deformity in the sacrum. These characteristics can be used to distinguish between pediatric and adult slippage.

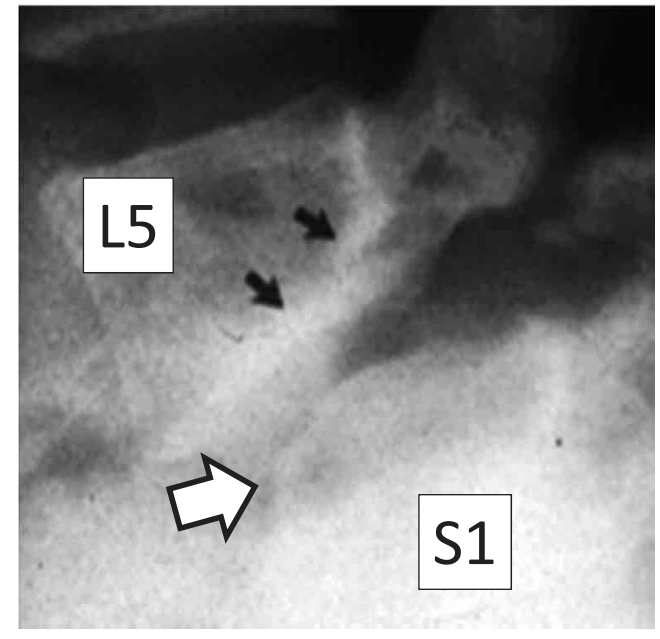

(a) Pediatric slip

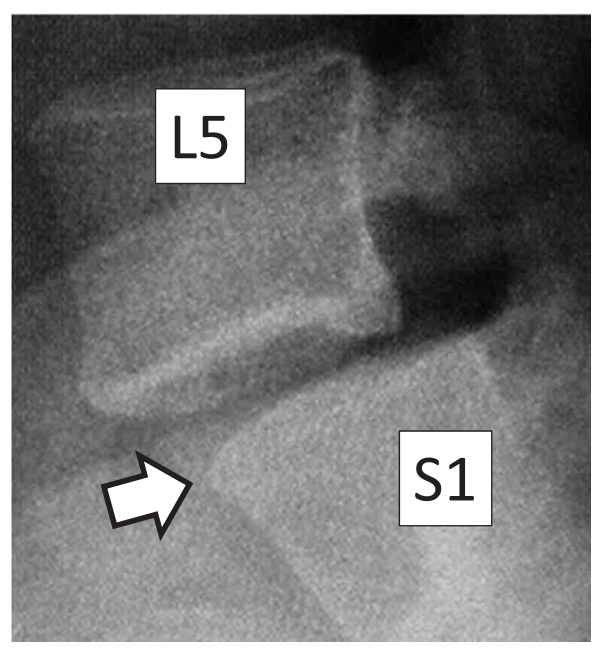

(b) Adult slip

Figure 10 : Plain radiographs of pediatric and adult slippage of the spondylolytic spine. (a) Pediatric slippage : Black arrows indicate a deformity in the L5 vertebral body and the vertebral body is wedge-shaped. The white arrow indicates poor development of the anterior edge of the S1 vertebral body. (b) Adult slippage : no deformity in the sacrum is evident and the anterior edge of the sacrum is sharp as normal (arrow). 


\section{CONCLUSION}

Figure 11 illustrates the Tokushima theory of growth plate slippage in pediatric spondylolisthesis. First, the pars stress fracture progresses to pseudoarthrosis, and these defects may alter the biomechanics affecting the growth plate. In the pediatric spine with pars defects, the mechanical stress in the growth plate increases, which through repetitive lumbar motions creates a stress fracture of the growth plate, ultimately leading to slippage at the growth plate.

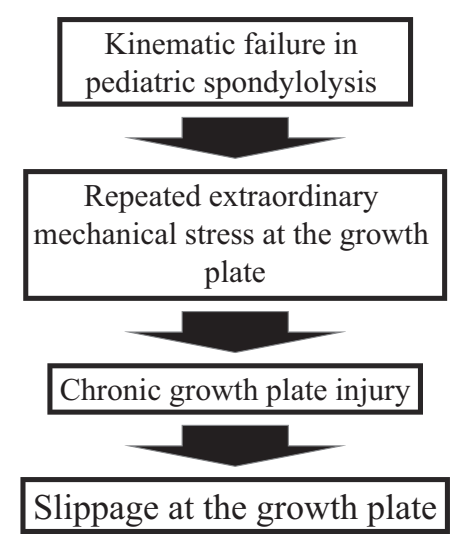

Figure 11 : The Tokushima theory of growth plate slippage in pediatric spondylolisthesis.

\section{REFERENCES}

1. Sairyo K, Katoh S, Sakamaki T, Komatsubara S, Endo K, Yasui $\mathrm{N}$ : Three successive stress fractures at the same verebral level in an adolescent baseball player. Am J Sports Med 31 : 606-10, 2003

2. Sairyo K, Katoh S, Sasa T, Yasui N, Goel VK, Vadapalli S, Masuda A, Biyani A, Ebraheim N : Athletes with unilateral spondylolysis are at risk of stress fracture at the contralateral pedicle and pars interarticularis : a clinical and biomechanical study. Am J Sports Med 33 : 583-90, 2005

3. Wiltse LL, Widell EH Jr, Jackson DW : Fatigue fracture : the basic lesion is isthmic spondylolisthesis. J Bone Joint Surg [Am] 57-A : 17-22, 1975

4. Laurent LE, Osterman K: Operative treatment of spondylolisthesis in young patients. Clin Orthop Relat Res (117) : 8591, 1976

5. Fujii K, Katoh S, Sairyo K, Ikata T, Yosui N : Union of defects in the pars interartic-ularis of the lumbar spine in children and adolescents : the radiological outcome after conservative treatment. J Bone Joint Surg [Br] 86-B : 225-31, 2004

6. Tezuka F, Sairyo K, Sakai T, Dezawa A : Etiology of Adultonset Stress Fracture in the Lumbar Spine. J Spinal Disord Tech : 2014 [Epub ahead of print]

7. Boxall D, Bradford DS, Winter RB, Moe JH : Management of severe spon-dylolisthesis in children and adolescents. J Bone Joint Surg [Am] 61 : 479-95, 1979

8. Seitsalo S, Osterman K, Hyvarinen H, Tallroth K, Schlenzka $\mathrm{D}$, Poussa M : Progression of spondylolisthesis in children and adolescents : A long-term fol-low-up of 272 patients. Spine $16: 417-21,1991$

9. Turner RH, Bianco AJ Jr : Spondylolysis and spondylolisthesis in children and teenagers. J Bone Joint Surg [Am] 53 : 1298306,1971
10. Fredrickson BE, Baker D, McHolick WJ, Yuan HA, Lubicky JP : The natural history of spondylolysis and spondylolisthesis. J Bone Joint Surg [Am] 66 : 699-707, 1984

11. Laurent LE, Einola $S$ : Spondylolisthesis in children and adolescents. Acta Orthop Scand 31 : 45-64, 1964

12. Sairyo K, Katoh S, Ikata T, Fujii K, Kajiura K, Goel VK : Development of spondylolytic olisthesis in adolescents. Spine J 1(3) : 171-5, 2001

13. Rowe GG, Roche MB : The etiology of separate neural arch. J Bone Joint Surg Am 35 : 102-10, 1953

14. Rosenberg NJ, Bargar WL, Friedman B : The incidence of spondylolysis and spondylolisthesis in nonambulatory patients. Spine (Phila Pa 1976) 6(1) : 35-8, 1981

15. Sakai T, Yamada H, Nakamura T, Nanamori K, Kawasaki Y, Hanaoka N, Nakamura E, Uchida K, Goel VK, Vishnubhotra S, Sairyo K : Lumbar Spinal Disorders in Patients With Athetoid Cerebral Palsy : A Clinical and Biomechanical Study. Spine 31(3) : E66-E70, 2006

16. Sairyo K, Katoh S, Takata Y, Terai T, Yasui N, Goel VK, Masuda A, Vadapalli S, Biyani A, Ebraheim N : MRI signal changes of the pedicle as an indicator for early diagnosis of spondylolysis in children and adolescents. A clinical and biomechanical study. SPINE $31: 206-211,2006$

17. Sairyo K, Sakai T, Yasui N : Conservative treatment of lumbar spondylolysis in childhood and adolescence : the radiological signs which predict healing. J Bone Joint Surg [Br] 91-B : 206-9, 2009

18. Sakai T, Sairyo K, Takao S, Nishitani H, Yasui N : Incidence of Lumbar Spondylolysis in the General Population in Japan Based on Multi-detector CT Scans from 2,000 Subjects. SPINE 21 (34) : 2345-2350, 2009

19. Sakai T, Sairyo K, Mima S, Yasui N : Significance of Magnetic Resonance Imaging Signal Change in the Pedicle in the Management of Pediatric Lumbar Spondylolysis. Spine (Phila Pa 1976) 35(14) : E641-5, 2010

20. Sairyo K, Sakai T, Yasui N, Dezawa A : conservative treatment for pediatric lumbar spondylolysis to achieve bone healing using a hard brace : what type and how long? J Neurosurg Spine 16 (6) : 610-4, 2012, Epub 2012 Apr 20.

21. Sairyo K, Goel VK, Biyani A, Ebraheim N, Liu J : Decompression surgery for lumbar spondylolysis without fusion : A review article. Internet J Spine Surg 2(2) : 2006

22. Sairyo K, Goel VK, Faizan A, Vadapalli S, Biyani S, Ebraheim N : Buck's Direct Repair of Lumbar Spondylolysis Restores Disc Stresses at the Involved and Adjacent Levels. Clin Biomech (Bristol, Avon) 21(10) : 1020-6, 2006

23. Kajiura K, Katoh S, Sairyo K, Ikata T, Goel VK, Murakami $\mathrm{RI}$ : Slippage mechanism of pediatric spondylolysis : biomechanical study using immature calf spines. Spine 26(20) : 220812 ; discussion 2212-3, 2001

24. Saraste $\mathrm{H}$ : Spondylolysis and spondylolisthesis. Acta Orthop Scand Suppl 251:84-6, 1993

25. Seitsalo S, Schlenzka D, Poussa M, Osterman K: Disc degeneration in young patients with isthmic spondylolisthesis treated operatively or conservatively : a long-term follow-up. Eur Spine J 6(6) : 393-7, 1997

26. Farfan HF, Osteria V, Lamy C : The mechanical etiology of spondylolysis and spondylolisthesis. Clin Orthop Relat Res (117) : 40-55, 1976

27. Ikata T, Miyake R, Katoh S, Morita T, Murase M : Pathogenesis of sports-related spondylolisthesis in adolescents. Radiographic and magnetic resonance imaging study. Am J Sports Med 24(1) : 94-8, 1996

28. Sairyo K, Goel VK, Grobler LJ, Ikata T, Katoh S: The pathomechanism of isthmic lumbar spondylolisthesis. A biomechanical study in immature calf spines. Spine 23(13) : 1442-6, 
1998

29. Konz RJ, Goel VK, Grobler LJ, Grosland NM, Spratt KF, Scifert JL, Sairyo K: The pathomechanism of spondylolytic spondylolisthesis in immature primate lumbar spines in vitro and finite element assessments. Spine 26(4) : E38-49, 2001

30. Sakamaki T, Sairyo K, Katoh S, Endo H, Komatsubara S, Sano $\mathrm{T}$, Yasui $\mathrm{N}$ : The pathogenesis of slippage and deformity in the pediatric lumbar spine : a radiographic and histologic study using a new rat in vivo model. Spine 28(7) : 645-50, 2003

31. Sairyo K, Katoh S, Sakamaki T, Inoue M, Komatsubara S, Sano T, Goel VK, Yasui N : Vertebral forward slippage in immature lumbar spine occurs following epiphyseal separation and its occurrence is unrelated to disc degeneration: Is the pediatric spondylolisthesisa physis stress fracture of vertebral body? Spine 29(5) : 524-527, 2004

32. Komatsubara S, Sairyo K, Katoh S, Sakamaki T, Yasui N : High-grade slippage of the lumbar spine in a rat model of spondylolisthesis : effects of cyclooxygenase- 2 inhibitor on its deformity. SPINE 31(16) : E528-34, 2006

33. Higashino K, Sairyo K, Katoh S, Sakamaki T, Komatsubara S, Yukata K, Hibino N, Kosaka H, Yasui N : Vertebral rounding deformity with pediatric spondylolisthesis occurs due to failure of endochondral ossification of the growth plate. Radiological, histological and immunohistochemical analysis of a rat spondylolisthesis model-Spine 32(25) : 2839-45, 2007

34. Vadapalli S, Sairyo K, Goel VK, Robon M, Biyani A, Khandha A, Ebraheim NA : Biomechanical rationale for using peek spacers for lumbar interbody fusion-a finite element study. Spine 31(26) : E992-8, 2006

35. Grauer JN, Biyani A, Faizan A, Kiapour A, Sairyo K, Ivanov A, Ebraheim NA, Serhan H, Patel TCh, Goel VK : Biomechanics of two level Charite artificial disc placement in comparison to fusion plus single level disc placement combination. Spine J 6(6) : 659-66, 2006

36. Sairyo K, Goel VK, Masuda A, Biyani A, Ebraheim N, Mishiro T, Terai T : Biomechanical Rationale of Endoscopic Decompression for Lumbar Spondylolysis As An Effective Minimally
Invasive Procedure-A study based on the Finite Element Analysis. Minimally Invasive Neurosurg 48 : 119-122, 2005

37. Sairyo K, Biyani A, Goel VK, Leaman D, Booth R, Thomas J, Gehning D, Vishnubhotla S, Ebraheim N : Pathomechanism of ligamentum flavum hypertrophy : a multidisciplinary investigation based on clinical, biomechanical, histological, and biological assessments. SPINE 30 (23) : 2649-2656, 2005

38. Sairyo K, Goel VK, Vadapalli S, Vishnubhotla S, Biyani A, Ebraheim N, Terai T, Sakai T : Biomechanical comparison of lumbar spine with or without spina bifida occulta. A finite element analysis. Spinal Cord 44(7) : 440-4, 2006, Epub 2005 Nov 29.

39. Sairyo K, Goel VK, Masuda A, Vishnubhotla S, Biyani A, Ebraheim N, Murakami R, Yonekura D : Three Dimensional Finite Element Analysis of the Pediatric Lumbar Spine : Part I : Pathomechanism of apophyseal bony ring fracture. Eur Spine J 15 : 923-929, 2006, April 14, e-pub ahead

40. Sairyo K, Goel VK, Masuda A, Vishnubhotla S, Biyani A, Ebraheim N, Murakami R, Yonekura D : Three Dimensional Finite Element Analysis of the Pediatric Lumbar Spine : Part II : Biomechanical change as the initiating factor for pediatric isthmic spondylolisthesis at the growth plate. Eur Spine J 15 : 930-935, 2006, April 14, e-pub ahead

41. Faizan A, Sairyo K, Goel VK, Biyani A, Ebraheim N, Sakai $\mathrm{T}$ : Biomechanical rationale of ossification of the secondary ossification center on apophyseal bony ring fracture : A Biomechanical study. Clin Biomech 22 : 1063-1067, 2007

42. Stone AT, Tribus CB : Acute progression of spondylolysis to isthmic spondylolisthesis in an adult. Spine (Phila Pa 1976) 27(16) : E370-2, 2002

43. Beutler WJ, Fredrickson BE, Murtland A, Sweeney CA, Grant $\mathrm{WD}$, Baker $\mathrm{D}$ : The natural history of spondylolysis and spondylolisthesis : 45-year follow-up evaluation. Spine (Phila Pa 1976) 28(10) : 1027-35, 2003

44. Floman Y : Progression of lumbosacral isthmic spondylolisthesis in adults. Spine (Phila Pa 1976) 25(3) : 342-7, 2000 